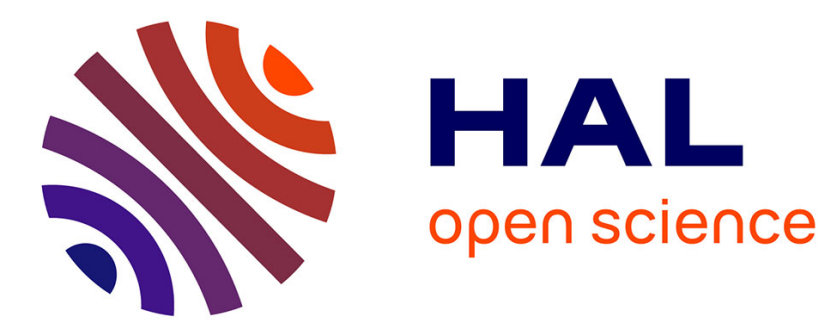

\title{
Identifying lakebed nature: is it feasible with a combination of echosounder and Sonar 5-pro?
}

Thomas Poulain, Christine Argillier, Muriel Gevrey, Jean Guillard

\section{To cite this version:}

Thomas Poulain, Christine Argillier, Muriel Gevrey, Jean Guillard. Identifying lakebed nature: is it feasible with a combination of echosounder and Sonar 5-pro?. Advances in Oceanography and Limnology, 2011, 2 (1), pp.49-53. hal-02642736

\section{HAL Id: hal-02642736 \\ https://hal.inrae.fr/hal-02642736}

Submitted on 28 May 2020

HAL is a multi-disciplinary open access archive for the deposit and dissemination of scientific research documents, whether they are published or not. The documents may come from teaching and research institutions in France or abroad, or from public or private research centers.
L'archive ouverte pluridisciplinaire HAL, est destinée au dépôt et à la diffusion de documents scientifiques de niveau recherche, publiés ou non, émanant des établissements d'enseignement et de recherche français ou étrangers, des laboratoires publics ou privés. 
This article was downloaded by: [Guillard, Jean]

On: 17 June 2011

Access details: Access Details: [subscription number 938735790]

Publisher Taylor \& Francis

Informa Ltd Registered in England and Wales Registered Number: 1072954 Registered office: Mortimer House, 3741 Mortimer Street, London W1T 3JH, UK

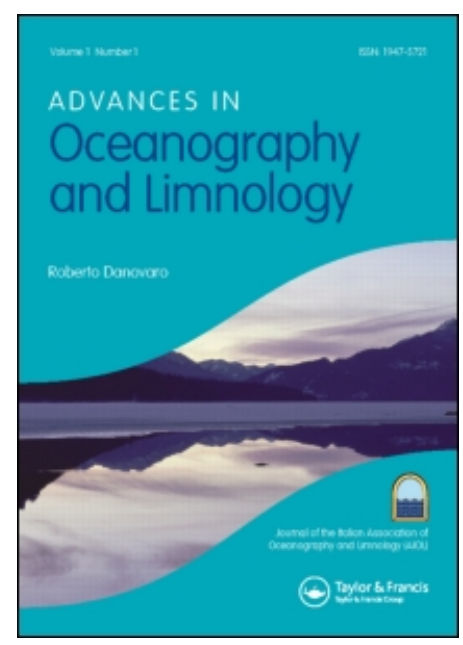

\section{Advances in Oceanography and Limnology}

Publication details, including instructions for authors and subscription information: http://www.informaworld.com/smpp/title $\sim$ content=t911208256

\section{Identifying lakebed nature: is it feasible with a combination of echosounder and Sonar5-pro?}

Thomas Poulain ${ }^{\mathrm{a}}$; Christine Argillier ${ }^{\mathrm{a}}$; Muriel Gevrey ${ }^{\mathrm{a}}$; Jean Guillard ${ }^{\mathrm{b}}$

${ }^{a}$ Pôle Hydroécologie plans d'eau Onema/CEMAGREF, Aix-en-Provence, France ${ }^{\mathrm{b}}$ Institut National de

la Recherche Agronomique, UMR CARRTEL, Thonon-les-Bains, France

Online publication date: 17 June 2011

To cite this Article Poulain, Thomas, Argillier, Christine, Gevrey, Muriel and Guillard, Jean(2011) 'Identifying lakebed nature: is it feasible with a combination of echosounder and Sonar5-pro?', Advances in Oceanography and Limnology, 2: $1,49-53$

To link to this Article: DOI: $10.1080 / 19475721.2011 .565803$

URL: http://dx.doi.org/10.1080/19475721.2011.565803

\section{PLEASE SCROLL DOWN FOR ARTICLE}

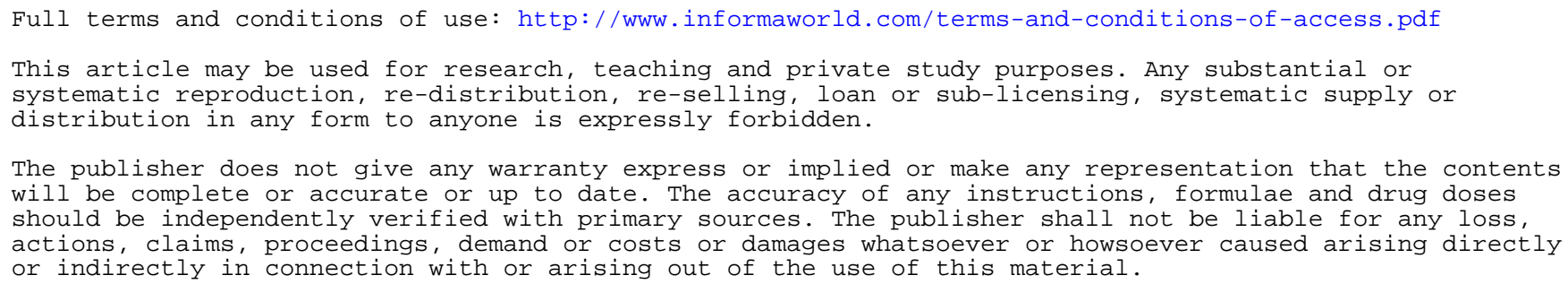




\title{
Identifying lakebed nature: is it feasible with a combination of echosounder and Sonar5-pro?
}

\author{
Thomas Poulain $^{\mathrm{a} *}$, Christine Argillier ${ }^{\mathrm{a}}$, Muriel Gevrey ${ }^{\mathrm{a}}$ and Jean Guillard ${ }^{\mathrm{b}}$ \\ ${ }^{a}$ Pôle Hydroécologie plans d'eau Onema/CEMAGREF, Aix-en-Provence, France; \\ ${ }^{b}$ Institut National de la Recherche Agronomique, UMR CARRTEL, Thonon-les-Bains, France
}

(Received 22 September 2010; final version received 11 February 2011)

\begin{abstract}
Since a few decades, underwater substrata can be characterized by methods using acoustic technology. Compare to traditional in situ grabbing techniques (bottom grab sampler, video camera,...), these methods allow a better spatial resolution. Until today, these acoustical techniques required specialized signal processing materials. This document presents works about lakebed classification using single beam echo sounder and a post processing software (Sonar5) dedicated to the estimation of fish biomass. Indeed, an underwater substrate analyzing module based on the theory developed by Orlowski (Oceanologia 19 (1984), pp. 61-78) has just been implemented in the sofware. An optimum configuration have been selected and permitted to classify four different natures of substrata: silt, sand, sand \& stones, and rock. A substrata nature map of an area known as an arctic charr (emblematic salmonid of the alpine big lakes) reproduction site has been done and shows the system's performances.
\end{abstract}

Keywords: lakebed; Sonar5-pro; acoustic; echo sounder

Usual techniques implemented to determine the nature of underwater substrata, i.e. bottom grab sampling or direct visualization with video cameras, are difficult to manage in some areas like deep water areas. Moreover, their low spatial resolutions are a major problem. In the 1980s, more reliable acoustic techniques using echo sounders were established based on Orlowski's work [1]. The first system which specialized in acoustic seabed classification was the 'RoxAnn' system (www.sonavision.co.uk), followed by the 'QTC View' (www.questertangent.com) system a few years later. Both of these devices are coupled with a single beam echo sounder and analyze the returned signal. For that, two different approaches have been developed: 'RoxAnn' analyzes the energies of a part of the first echo returned by the bottom and the entire second one, while 'QTC View' extracts shape parameters from the first echo.

Sonar5-pro software [2], used by a lot of researchers, analyzes acoustic signals for biomass estimation, size of structures, behavior of lake fish populations [3-5] and has recently added a new module (seabed classification, Sonar5-pro, ver 5.9.8) to classify underwater substrata, derived from Orlowski's [1] work on first and second echoes. For each pulse delivered by the echo sounder, the 'seabed classification' module returns four energies related to the first and second echoes. Indeed, both echoes are split in two parts: the first one begins when an echo is detected and is one pulse length long and the second

*Corresponding author. Email: tpoulain@dijon.inra.fr 
part begins at the end of the first part and is three pulse lengths long [1]. The energy of the tail of the first echo (called DecaySv1 by Sonar5-pro and E1 by RoxAnn) is directly delivered by Sonar5-pro and the entire energy of the second echo (called E2 by RoxAnn) is assessed combining its two energies (AttackSv2 and DecaySv2 in Sonar5-pro). These two parameters characterize the substrate: E1 gives information about the roughness and E2 about the hardness of the surface of the bottom [1,6]. To classify substrata the general method consists of building a reference database of clusters using E1/E2 coordinates [7], where each of these clusters defines a lakebed type validated in situ by direct observations or grab analyses (ground truth). All of the [E1,E2] data belonging to the same type of lakebed are grouped together and the extremities used to define the clusters' limits. When the database is complete, each of the [E1, E2] couples from unknown substrata are plotted against the cluster limits of the database to determine their nature. To determine the quality of the data which could be available for the lake research and management community, it is important to test the application of this module.

From March to June 2010, eight surveys on different lakes and substrata were carried out to create a substrate reference database using a Simrad EK 60 echosounder, delivering acoustic pulses of $70 \mathrm{kHz}$. Five different powers $(120,200,320,400$, and $800 \mathrm{~W})$ and four pulse lengths $(0.128,0.256,0.512$, and $1.024 \mathrm{~ms})$, those most commonly used in fisheries acoustics [8], were tested to determine the best performing parameters. According to this analysis, an output power of $400 \mathrm{~W}$ and a pulse length of $0.512 \mathrm{~ms}$ were selected to work with our $70 \mathrm{kHz}$ acoustic wave. The power determination was a compromise to make the system efficient from $5 \mathrm{~m}$ to more than $140 \mathrm{~m}$ deep, indeed in the shallow areas a saturation phenomenon occurs. At $800 \mathrm{~W}$ and for all the pulse lengths, between 0 and $7 \mathrm{~m}$ deep Sonar5-pro is not able to deliver E1 and E2 because of the excessive amount of energy returned by the bottom but at $400 \mathrm{~W}$ the saturation threshold is only at $5 \mathrm{~m}$. The $0.512-\mathrm{ms}$ pulse length was chosen due to its lower variability on the couple [E1, E2]. To determine the variability for each given pulse length, a statistical study was done using the average Euclidean distances of a series of points as a variability indicator. The four pulse lengths were tested on nine different sites (four series of 350 pings on each site) and in $66 \%$ of cases $0.512 \mathrm{~ms}$ is the less variable pulse length.

All of the data were recorded using these parameters, $400 \mathrm{~W}$ and $0.512 \mathrm{~ms}$, on two natural French lakes (Leman, Bourget) and one reservoir (Bimont, France) in moored positions, using an Ekman grab sampler and a video camera for in situ validation. Four classes of lakebed were determined with 25 samples at different depths, using TimeVaried-Gain function to compensated transmission loss, (i.e. 25 couples [in situ observations; acoustic measurements]): mud: $\varnothing<20 \mu \mathrm{m} \quad(13$ samples $)$, sand: $20 \mu \mathrm{m}<\varnothing<2 \mathrm{~mm}$ (4 samples), sand \& stones: $2 \mathrm{~cm}<\varnothing<20 \mathrm{~cm}$ for the stones (3 samples), blocks: $\varnothing>20 \mathrm{~cm}$ i.e. boulders or cobbles (5 samples) (Figure 1). This classification is coarse but covers the whole range of the main substrata found in lakes [9]; all classes are well defined, except in a few cases where it is impossible to tell the difference between sand and sand \& stones or between mud and blocks, as happens with commercial devices (RoxAnn or QTC View) [10].

This calibration procedure was done from a stationary vessel whereas lakebed determinations of unknown areas have to be done with a moving vessel. Therefore, acquisitions in fixed position and acquisitions made with a four knots speed, common practice in fish surveys, were compared. For this step, moving acquisitions were done using the optimum pulse parameters $(400 \mathrm{~W}, 0.512 \mathrm{~ms})$. On the path tracing by the moving vessel, seven fixed acquisitions were carried out using the same parameters. The results 


\section{Clusters of lakebed natures}

E2 (dB)

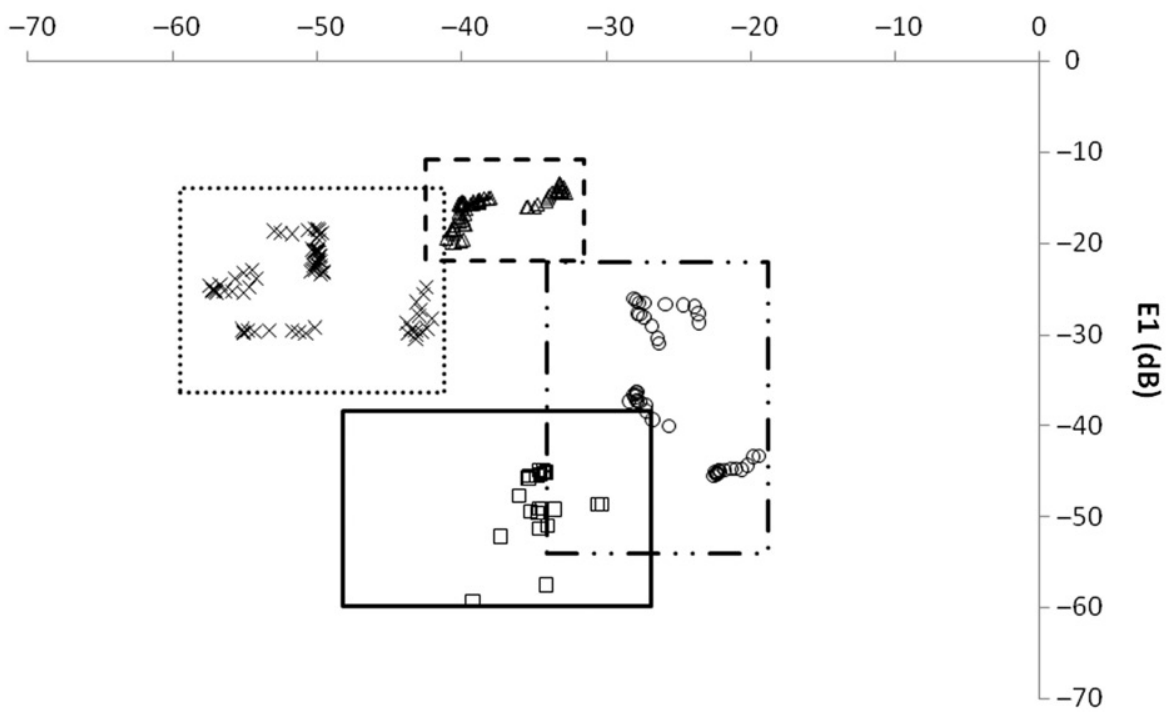

Figure 1. Clusters of each substrate nature plotted in the E2/E1 reference made with the in situ validation. Some points used to create these clusters are also plotted. Cross represent mud, triangles: blocks, circles: sand \& stones, squares: sand.

obtained at exactly the same position for both moving and fixed, thanks to a GPS, were compared and were similar: they are superimposed in the E1/E2 space. We highlight here the possible use of the reference database in moving surveys, confirming previous results [10].

This system, able to classify four types of lakebeds, was then applied on a $3-\mathrm{km}^{2}$ area known to be an arctic charr (Salvelinus alpinus) spawning site [11] in lake Leman. The system was coupled to a GPS and each sample, i.e. each substrate acoustic response, was recorded with its position and after comparison with the reference database, a substrate nature is given to each georeferenced sample. Then, the results can be expressed as a percentage of the number of samples belonging to each class found compared to the total number of acquisitions: mud (53\%), blocks (39\%), unknown (9\%). A map of the nature of the lakebed in this area (Figure 2) was made using Surfer software based on the "nearest neighbor interpolation'. This map gives an illustration of the distribution of the different substrata types, which some of them are typical of the spawning site of arctic charr. The interest of such a representation is the ability to compare maps over time, in one place, in order to analyze the evolution of the importance of mud versus blocks. It can also be used as a tool to follow the quality of fish habitats, and in the case of restoration of such areas, to survey the effected change over time.

This work using the capacity of acoustics to determine lakebed nature confirms that Sonar5-pro can be a useful low cost tool to classify lakes' substrata. Evolution of fish spawning areas, in time and space, could be monitored, particularly on restored sites, as was shown here for arctic charr spawning areas in Geneva lake [11]. Substrate is a morphological descriptor of a lake which can be linked to other biological communities. It 


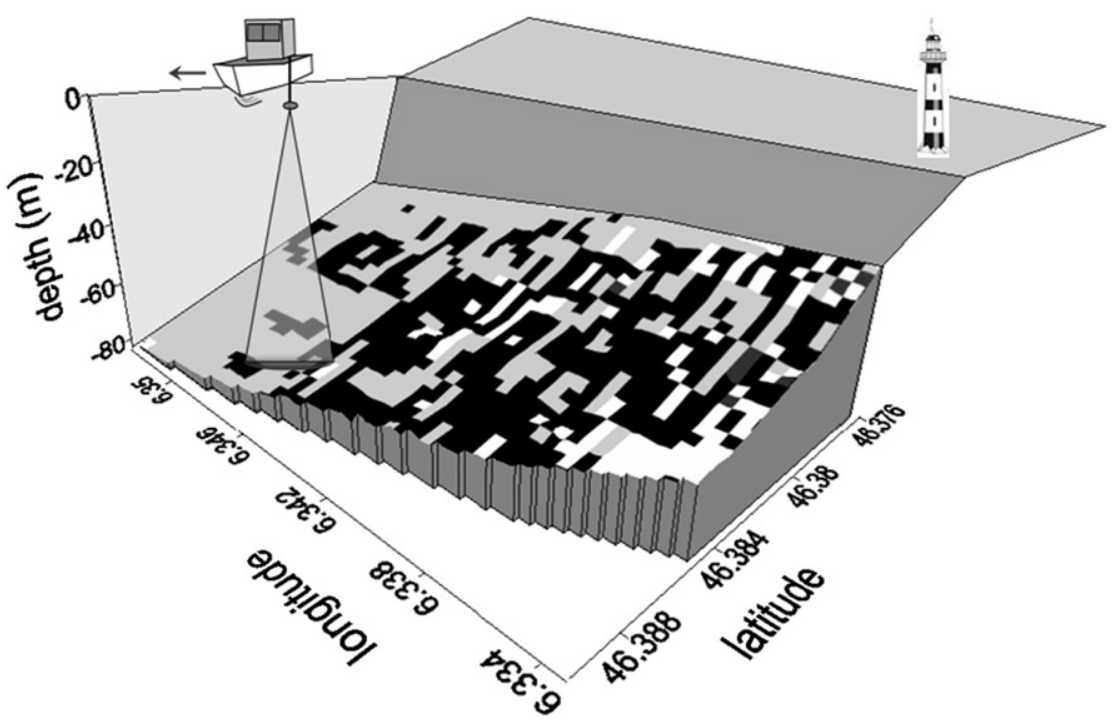

Figure 2. Lakebed classification map of an area known to be a spawning site of arctic charr in Lake Leman. Grey color represents a mud type substrate, black: blocks and white: unknown. A picture of a lighthouse permits to localize the shore easily and a boat with the acoustic beam is represented.

can explain, for example, benthic macrofauna distribution [12]. More generally, it is also related to the water quality of aquatic systems. Consequently, this assessment is particularly relevant from a lake management perspective. Further studies will be undertaken to add other substrata natures to our reference database and then to improve the resolution of discrimination.

\section{Acknowledgments}

This work was financed by the ONEMA (The French National Agency for Water and Aquatic Environments). We would like to thank Helge Balk and Noela Sànchez for their help in using the seabed module on Sonar5-pro. We also acknowledge Jean-Christophe Hustache, Cédric Lanoiselee, Samuel Alleaume, and Pascal Chifflet for their help during the acoustic surveys.

\section{References}

[1] A. Orlowski, Application of multiple echoes energy measurements for evaluation of sea bottom type, Oceanologia 19 (1984), pp. 61-78.

[2] H. Balk and T. Lindem, Sonar 4, Sonar 5, Sonar 6 - Post-processing Systems. Operator Manual, University of Oslo, Norway, 2006.

[3] I. Djemali, R. Toujani, and J. Guillard, Hydroacoustic fish biomass assessment in man-made lakes in Tunisia: Horizontal beaming importance and diel, Aquat. Ecol. 43 (2009), pp. 1121-1131.

[4] M. Godlewska, M. Colon, L. Doroszczyk, B. Długoszewski, C. Verges, and J. Guillard, Hydroacoustical measurements at two frequencies: 70 and $120 \mathrm{kHz}$ - consequences on fish stock estimation, Fish. Res. 96 (2009), pp. 11-16. 
[5] T. Mehner, S. Busch, I.P. Helland, M. Emmrich, and J. Freyhof, Temperature related nocturnal vertical segregation of coexisting coregonids, Ecol. Freshwater Fish, (2010). doi: 10.1111/j.16000633.2010.00424.x (forthcoming).

[6] R.C. Chivers, N. Emerson, and D.R. Burns, New acoustic processing for underway surveying, Hydrograph. J. 56 (1990), pp. 8-17.

[7] J. Burczynski (1995). Available at http://www.biosonicsinc.com/doc_library/docs/ bottom_classification.pdf

[8] J. Guillard, M. Godlewska, M. Colon, L. Doroszczyk, and B. Długoszewski. Standardization of hydroacoustic methods-effect of pulse duration, 3rd International Conference and Exhibition of Underwater Acoustic Measurements: Technologies \& Results, Nafplion, Greece, 2009.

[9] R. Pourriot and M. Meybeck, Limnologie générale, Masson, Paris, 1995.

[10] L.J. Hamilton, P.J. Mulhearn, and R. Poeckert, Comparison of RoxAnn and QTC View acoustic bottom classification system performance for the Cairns area, Great Barrier Reef, Australia, Continental Shelf Res. 19 (1999), pp. 1577-1597.

[11] J.F. Rubin, Les sites de reproduction de l'omble chevalier du Léman ont-ils évolué de 1981 à 2005?, Arch. des Sci. 58 (2005), pp. 201-230.

[12] K.T. Tolonen, H. Hamalainen, I.J. Holopainen, and J. Karjalainen, Influences of habitat type and environmental variables on littoral macroinvertebrate communities in a large lake system, Archiv Fur Hydrobiologie 152 (1) (2001), pp. 39-67. 